\title{
QUEEN'S
UNIVERSITY
BELFAST
}

\section{Nonlinear numerical modelling of lightning strike effect on composite panels with temperature dependent material properties}

Abdelal, G., \& Murphy, A. (2014). Nonlinear numerical modelling of lightning strike effect on composite panels with temperature dependent material properties. Composite Structures, 109, 268-278.

https://doi.org/10.1016/j.compstruct.2013.11.007

Published in:

Composite Structures

Document Version:

Peer reviewed version

Queen's University Belfast - Research Portal:

Link to publication record in Queen's University Belfast Research Portal

Publisher rights

NOTICE: this is the author's version of a work that was accepted for publication in Composite Structures. Changes resulting from the publishing process, such as peer review, editing, corrections, structural formatting, and other quality control mechanisms may not be reflected in this document. Changes may have been made to this work since it was submitted for publication.

\section{General rights}

Copyright for the publications made accessible via the Queen's University Belfast Research Portal is retained by the author(s) and / or other copyright owners and it is a condition of accessing these publications that users recognise and abide by the legal requirements associated with these rights.

Take down policy

The Research Portal is Queen's institutional repository that provides access to Queen's research output. Every effort has been made to ensure that content in the Research Portal does not infringe any person's rights, or applicable UK laws. If you discover content in the Research Portal that you believe breaches copyright or violates any law, please contact openaccess@qub.ac.uk. 


\section{Accepted Manuscript}

Nonlinear numerical modelling of lightning strike effect on composite panels with temperature dependent material properties

\section{G. Abdelal, A. Murphy}

PII:

$$
\text { S0263-8223(13)00587-4 }
$$

DOI: http://dx.doi.org/10.1016/j.compstruct.2013.11.007

Reference: COST 5463

To appear in:

\section{Composite Structures}

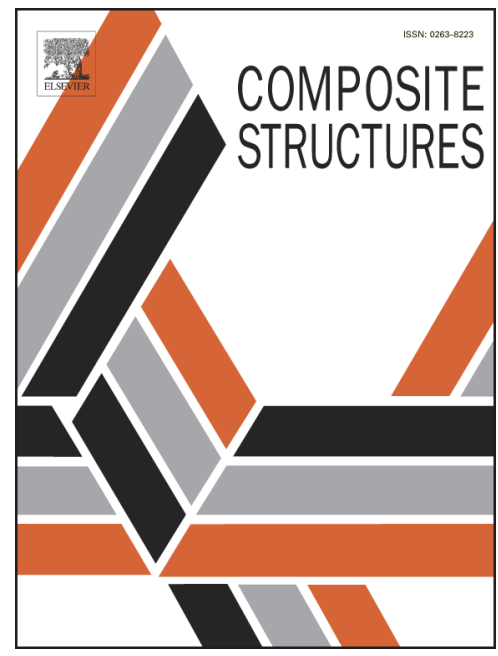

Please cite this article as: Abdelal, G., Murphy, A., Nonlinear numerical modelling of lightning strike effect on composite panels with temperature dependent material properties, Composite Structures (2013), doi: http:// dx.doi.org/10.1016/j.compstruct.2013.11.007

This is a PDF file of an unedited manuscript that has been accepted for publication. As a service to our customers we are providing this early version of the manuscript. The manuscript will undergo copyediting, typesetting, and review of the resulting proof before it is published in its final form. Please note that during the production process errors may be discovered which could affect the content, and all legal disclaimers that apply to the journal pertain. 


\title{
NONLINEAR NUMERICAL MODELLING OF LIGHTNING STRIKE EFFECT ON COMPOSITE PANELS WITH TEMPERATURE DEPENDENT MATERIAL PROPERTIES
}

\author{
G. Abdelal ${ }^{*}$, A. Murphy ${ }^{\dagger}$ \\ * Queen's University Belfast \\ University Road, BT7 1NN Belfast, UK \\ e-mail: g.abdelal@qub.ac.uk, web page: http:// http://www.qub.ac.uk/ \\ ${ }^{\dagger}$ Queen's University Belfast \\ University Road, BT7 INN Belfast, UK \\ e-mail:a.murphy@qub.ac.uk,web page: http://http://www.qub.ac.uk/
}

Key words: Composite materials, Finite Element Modelling, Coupled thermal-electric, temperature dependent, Decomposition kinetics, Endothermic heat, Conductivity.

\begin{abstract}
This paper presents a physics based modelling procedure to predict the thermal damage of composite material when struck by lightning. The procedure uses the Finite Element Method with non-linear material models to represent the extreme thermal material behaviour of the composite material (carbon/epoxy) and an embedded copper mesh protection system. Simulation predictions are compared against published experimental data, illustrating the potential accuracy and computational cost of virtual lightning strike tests and the requirement for temperature dependent material modelling. The modelling procedure is then used to examine and explain a number of practical solutions to minimize thermal material damage.
\end{abstract}

\subsection{Introduction}

Damage from lightning strike is a major challenge when using continuous Fiber-Reinforced Plastic (FRP) in the construction of aircraft. Lightning strike damage is due to high orthotropic electric resistivity of the FRP material, which leads to high thermal loads that cause decomposition of the plastic matrix and delamination of the plies. Experimental testing of lightning strike on aircraft materials and structures is expensive. Moreover, the large number of design parameters involved in FRP material, plus the design variables associated with an embedded lightning strike protection systems result in a vast design space, in which purely empirical design and development is very time consuming. Thus, protection systems are typically restricted to the most feasible design of a few considered, or are limited to a known, previously used design space. Unfortunately this can result in non-optimum designs being selected which can in turn cause problems at a later design stage.

The aim of this paper is to formulate a coupled thermal-electrical Finite Element analysis 
procedure to enable the investigation of the design variables that control lightning strike damage in epoxy/graphite FRP material. The major contribution of this is the formulation and verification of temperature dependent material properties, a key attribute not considered within previous literature. The proposed modelling procedure is applied to model a test specimen plate and the results verified against published experimental data, illustrating the potential accuracy and computational cost of virtual lightning strike tests and the requirement for temperature dependent material modelling. The modelling procedure is then applied to a number of practical lightning strike protection systems and the simulation results used to further understand, and for the first time to quantify, the physical behaviour which minimises the level of thermal material damage.

Lightning strike is made of plasma at $30,000 \mathrm{~K}$ degrees temperature, and electrons that progress at speeds of higher than $5,000 \mathrm{~m} / \mathrm{sec}$, to conduct $39.55 \times 10^{3} \mathrm{Joule} / \mathrm{Ohm}$ of energy (40 kA strike) within micro-seconds. Lightning strikes have significant effects on structures; resistive heating, magnetic forces, and overpressure. Previous researchers investigated these direct effects, assuming for example that damage in composite laminates is due to overpressure only without considering the effect of resistive heating [1,2,3]. Others investigated the effect due to resistive heating [4] as the main source of damage to the composite material, but applied highly idealised electric loading in numerical simulations, and used temperature independent material properties. Yet their general approach is unique, using coupled electrical/thermal FE analysis. This work built on this approach, introducing temperature dependent material properties, char material properties to simulate material status after decomposition, gas material properties to simulate material ablation status, and modelling the complex physics of protection systems using UMATH material subroutine (available in ABAQUS). Thus this paper is the first to capture many aspects of the Multiphysics that interact within lightning strikes. Simulation of the protection system included modelling melting, evaporation, and ablation, while interacting with the composite panel through temperature dependent thermal conductance properties.

\subsection{Background}

\subsection{Lightning strike physics}

The physical consequences of a lightning strike on an aircraft can be summarised as;

- Resistive heating at the lightning arc contact point which decomposes the FRP resin.

- An overpressure due to the explosion of the lightning channel, which leads to the propagation of a strong shock wave in a radial direction away from the arc. The explosion is due to the fast increase in the arc temperature in the conducting channel, up to $30,000 \mathrm{~K}$ within a time interval of a few microseconds.

A magnetic force due to fast conduction in any metallic component, including for example a metallic element used as part of a lightning protection system.

In order to minimise the damage of a lightning strike on current FRP aircraft components a metallic mesh located at the surface of the component or special types of conducting paints are used to shield and protect the underlying load bearing FRP material. If we consider for example a copper mesh based protection system, the copper will have a melting temperature of the order of 1,083 $\mathrm{C}\left(T_{m}\right)$, a boiling temperature of 2,800 $\mathrm{C}\left(T_{b}\right)$ and a critical temperature of $8,000 \mathrm{C}\left(T_{c}\right)$. Additionally the vaporization temperature of the copper will be a function of the local pressure $P$ and thus given the presence of the shock wave it is possible that vaporization could occur below the boiling temperature. Consequently when a copper mesh 
embedded at the surface of a FRP component is subjected to a high energy electric load complicated coupled physical processes ensue. The copper surface heats up, melts, vaporizes and once the surface temperature reaches approximately $90 \%$ of the critical temperature explosive boiling occurs, which results in ejection of a mixture of vapour and liquid droplets. Considering the behaviour of typical thermosetting plastics, when subjected to increasing temperature the material will decompose (between 300 and $500 \mathrm{C}$ ). Above 500 the material will be a char, and ablation will begin above 3,000 C. Between and throughout these phases the material's thermal and electrical properties will change with temperature. Finally, carbon fibre tows subjected to increasing temperature will also char and ultimately ablate $\left(3,316 \mathrm{C}^{\mathrm{O}}\right)$; again thermal and electrical properties will change with phase and temperature.

\subsection{Preceding literature}

Haigh [1] focused on the mechanical effects of lightning strike on test panels, using mechanical and optical instruments to measure the force imparted by an electric arc on a panel over time. The extracted force measurements were then compared to equivalent tests in which only mechanical impulse loading was applied. Gineste et al. [2] followed the work done by Haigh [1] and used visual interferometric optical methods to measure deflections at multiple locations over time. A model was developed to extract from the measured deflection the mechanical impulse induced by the strike. Lepetit et al. [3] presented further progress in the same research direction, considering the impact of explosive boiling of protection system paint and its influence on the induced FRP damage.

The methodologies of Haigh, Gineste and Lepetit $[1,2,3]$ ignore the electric properties of the material and the coupling between the electromagnetic and the thermal behaviours. This is significant as deformation and high thermal strains will result at the arc contact point due to the impact of the plasma of electrons at extreme temperature $\left(>30,000 \mathrm{~K}^{0}\right)$, and joule heating due to the electric resistivity of the material. The preceding models also ignored the decomposition of the epoxy material due to high thermal load and its effect on orthotropic electric/thermal conductivity of the material. Thus only magnetic and overpressure forces due to the electric arc strike are included and the influence of a major cause of damage, plasma and resistive heating has been neglected. Leptit [3] captures the effect of explosive boiling experimentally, but the applied numerical modelling, based on explicit dynamic analysis, again ignores the impact of coupling between the electromagnetic and the thermal behaviours.

Ogasawara, etc. [4], using coupled electromagnetic/thermal Finite Element (FE) simulations modelled lightning strikes numerically, including coupling between electromagnetic and thermal behaviour. The simulations considered specimens without lightning protection systems (i.e. a protective mesh or paint) and the associated complexity of modelling their electrical/thermal performance. However, Ogasawara etc. [4] simulations ignored the temperature dependency of the electrical/thermal material properties and used a technique for the application of the electric arc load which may produce inaccurate results. An explanation of a more accurate method to apply electric current is discussed later in this paper.

Chemartin, etc [5] presents a comprehensive survey of the thermal and mechanical direct effects of lightning strike on aircraft skin panels. They developed both numerical and experimental models to simulate the plasma between the cathode and the panel, capturing its temperature and conduction profile. They simulated the lightning strike in flight conditions to characterize the sweeping stroke process and to evaluate dwell time, which is an important parameter for the waveform definition to be applied on the swept zones of aircraft. Their experimental approach was very comprehensive, not only modelling the damage and electric 
spark generation in aircraft panels, but also modelling the electric arc physics. Using basic mathematical expressions they modelled the thermal and mechanical forces applied on aircraft panels, but did not model the panel structure, its interaction with the force applied or resulting panel damage.

Using experimental tests to study the impact of lightning strike is expensive and limited to studying the effect of a few parameters at a time, such as decomposition and delamination in the vicinity of the lightning strike. Using a purely empirical approach to optimize the performance of a lightning protection system is inevitably time consuming and expensive. Thus in this paper we build on the preceding work by proposing an improved technique to model the lightning strike effects on composite panel with and without a protection system. We address the resistive heating force and its interaction with the composite structure, and the protection system thermal performance. A coupled electromagnetic/thermal FE analysis is proposed with material properties modelled as functions of temperature. A user material subroutine is used to model the complex physical behaviour of the protection system. Magnetic forces and overpressure participation are addressed in the following work, where a coupled mechanical simulation is used and laminate delamination is modelled. Developing a numerical tool that models the complex physical process of lightning strike on composite panels with protection systems is essential for the efficient optimization of current lightning strike protection systems and developing new protection system concepts.

\subsection{Experimental setup}

There are generally two configurations of lightning strike test setup. The simplest configuration is for the specimen to be located on top of a copper plate. In the second configuration the specimen is supported at its two short ends between copper electrodes, which are encapsulated by non-conductive phenolic composite material, and whose position is adjusted to be in close contact with the specimen [5]. A spark generator is designed to simulate the impulse current waveform of lightning strike as described in MIL and SAE [6]. These waveforms represent idealized environments, which are to be applied to the aircraft components for analysis and/or testing. The waveforms are not intended to reproduce a specific lightning event, but they are intended to be composite waveforms whose effects upon aircraft are those expected from normal lightning. For each waveform, peak current amplitude, action integral and time duration are the primary parameters that dictate the response of the structure. Where the action integral is a measure of the intensity of the strike, and therefore a key measure to ensure a test strike accurately simulates real lightning event behaviour. Figure 1 depicts the four components of the direct strike lightning idealized current test waveform; component A (high current), B (intermediate current), C (continuing current), and D (restrike current). The current waveform characteristics can be described in equation form,

Electric Power $=V I=\left(\begin{array}{ll}I & R\end{array}\right) I=I^{2} R \quad \operatorname{Watt}(J / s)$

To express this as a thermal power dissipated per unit resistance,

$$
\frac{P}{R}=I, \text { Action Integral }(A I)=\int_{t 0}^{t f} I^{2}(t) d t \quad A^{2} s=J / O h m
$$

Electrical charge $(\mathrm{Q})=\int_{t 0}^{t f} I(t) d t \quad A s$

Waveform $\mathrm{D}$ is designed to represent a typical restrike, after the primary strike to the airframe, and is also used to certify the vast majority of the airframe structure. Waveform D 
calls for a maximum of $100 \mathrm{kA}$, released over less than $0.5 \mathrm{~ms}$, and an action integral of $250 \times 10^{3} \mathrm{~A}^{2} \mathrm{~s}$. However, strikes of $100 \mathrm{kA}$ prescribed by waveforms $\mathrm{D}$ are typically used to strike full-scale test articles or subcomponents that are representative of actual hardware, but are far too high a current to be used to inflict damage in coupon-sized articles, such as the ones used in this study. Herein strikes at $40 \mathrm{kA}$ are used to inflict different states of damage to the coupons, corresponding to action integral of $39.55 \times 10^{3} \mathrm{~A}^{2} \mathrm{~s}$.

$$
\begin{aligned}
& I(t)=43762.0\left(e^{-\alpha t}-e^{-\beta t}\right) \\
& \alpha=22708.0, \beta=1294530.0
\end{aligned}
$$

The experimental test results from Ogasawara etc. [4] are used for the verification of the numerical simulation in this paper. Figure 2 illustrates the test setup used.

\subsection{Finite Element model}

Coupled thermal-electrical FE analysis will be used to simulate the experimental test of applying a Waveform D strike to a composite panel specimen located on top of a copper plate. The simulation will consider an electric current applied at the composite panel centre. Appropriate electrical and thermal boundary conditions will be applied to represent the experimental setup. Temperature dependent thermal/electrical material properties will be modelled and the heat generated in the panel specimen due to heat resistivity will be modelled.

\subsection{Theoretical formulation}

A lightning strike (electric arc) can be described as a channel of negative electrons advancing at very high speed between two leaders (clouds to earth). Clouds act like a cathode with a negative electrode and are the source of electrons or the electron donor. The earth acts like an anode with a positive electrode and is the electron acceptor. The electric arc is a response to a breakdown due to excessive voltage applied to a gap between two electrodes. Once the breakdown occurs, an ionized region is formed in the gas between the two electrodes and current flows through the ionized region. For lightning, the arc velocity is around $2 \times 10^{5} \mathrm{~m} / \mathrm{s}$, carrying a charge of order 2 to $20 \times 10^{-4}$ Coulombs. Wagner [7] reported that the current channel has surge impedance of the order of $3000 \mathrm{Ohms}$ for return stroke of amplitude 100 $\mathrm{kA}$. This large impedance is due to the resistance associated with the collection of charge at the upper end of the lightning channel. Once the charge has been collected and the current in the channel reaches its final value, the longitudinal resistance becomes smaller, of the order of $500 \mathrm{Ohms}$. As noted earlier the energy released in the ionized region is enough to raise the temperature of the current path to $30,000 \mathrm{~K}$ (Plasma). Thus arc interaction with a structure will have both thermal and mechanical effects. The thermal effect is due to conduction of the plasma current to the aircraft surface and joule heat effect due to electric resistivity of the aircraft structure. The mechanical effects under magnetic and overpressure forces are not addressed in this paper. Magnetic forces exist in metallic structures, yet for composite structures, it is limited to the conducting protection layer. The thickness of the protection layer is small compared to the total thickness of the full composite panel, and thus the 
influence of magnetic forces can be ignored? Estimating the overpressure contribution requires a special set of experimental data, which will capture the displacement of the zone under lightning strike as a function of time. Then, a mechanical FE module may be integrated to the developed simulations to estimate the displacement beneath a lightning strike event due to thermal strains and ablation. Thus the displacement due to overpressure that is measured experimentally and the displacement due to thermal strains and ablation that is estimated numerically can be compared and the contribution distribution is defined.

Kaddani etc. [8] derived an equation to describe the conduction heat flux flows from arc plasma to an aircraft surface;

$$
Q_{A}=J\left(U_{a}+\Phi_{m a t}+\frac{5 k_{b}}{2 e}\left(T_{p l}-T_{m a t}\right)\right) \quad W / m^{2}
$$

- $\mathrm{J}$ is total current, $\mathrm{A} / \mathrm{m}^{2}$.

- $\mathrm{U}_{\mathrm{a}}$ is the voltage drop near the anodic surface, $\mathrm{V}$.

- $\Phi_{\text {mat }}$ is material work function due to current $(\mathrm{J}), \mathrm{V}$.

- $\mathrm{k}_{\mathrm{b}}$ is the Boltzmann constant.

- $\mathrm{e}$ is the electron electrical charge.

The conductive flux is negligible in the case of high current arcs [5], such as lightning, and thus is not considered in the proposed model.

The integral form of the Maxwell's equation of conservation of electric charge is given in

$$
\int_{S} J \cdot n d S=\int_{v} r_{c} d V
$$

Where $\mathrm{V}$ is any control volume whose surface is $\mathrm{S}, \mathrm{n}$ is the outward normal to $\mathrm{S}, \mathrm{J}$ is the electrical current density (current per unit area), and $r_{c}$ is the internal volumetric current source per unit volume. The flow of electrical current is described by Ohm's law, Equation (7).

$$
J=\sigma^{E} \cdot E=-\sigma^{E} \cdot \frac{\partial \phi}{\partial x}
$$

Where, $\varphi, E$, and $\sigma^{E}$ respectively signify the electrical potential, electrical field intensity, and electrical conductivity. The electrical conductivity, $\sigma^{\mathrm{E}}$, can be isotropic, orthotropic, or a fully anisotropic field and is independent of the electrical field, $E$. The amount of electrical energy dissipated by current flow in a conductor is described by Joule's law.

$$
P_{e c}=J \cdot E=\frac{\partial \varphi}{\partial x} \cdot \sigma^{E} \cdot \frac{\partial \varphi}{\partial x}=E \cdot \sigma^{E} \cdot E
$$

In a transient analysis an averaged value of $P_{e c}$ is calculated, Equation 9 , over the time increment, $\Delta t$.

$$
\begin{aligned}
P_{e c} & =\frac{1}{\Delta t} \int_{\Delta t} P_{e c} d t \\
& =E \cdot \sigma^{E} \cdot E-E \cdot \sigma^{E} \cdot \Delta E+\frac{1}{3} \Delta E \cdot \sigma^{E} \cdot \Delta E
\end{aligned}
$$

Where $E$, and $\sigma^{E}$ are values at time $t$ and $\Delta t$. The amount of this energy released as internal heat within the body is $\left(r=\eta_{v} P_{e c}\right)$, where $\eta_{v}$ is an energy conversion factor. 
Finally, the thermal energy balance is described in Equation 10, where $V$ is a volume of solid material, with surface area $S$; $\rho$ is the density of the material; $\dot{U}$ is the material time rate of the internal energy; $q$ is the heat flux per unit area of the body, flowing into the body; and $r$ is heat generated within the body.

$$
\int_{V} \rho \dot{U} \delta \theta d V=\int_{S} q d S+\int_{V} r d V
$$

The thermal performance of the composite laminate will be necessarily different from the performance of the lightning strike protection system. The composite material thermal performance may be characterized by resistive heating, decomposition, and ablation. Whereas the protection system thermal performance may be characterized by resistive heating, melting, evaporation, and ultimately explosive boiling. Oliveira [9] discussed the principles of phase explosion (explosive boiling). Normal boiling, heterogeneous nucleation, occurs at a temperature close to the boiling temperature $\left(T_{b}\right)$, but if superheating takes place and the temperature lies near the critical temperature $\left(T_{t c}\right)$, then phase explosion may occur by homogenous nucleation. Phase explosion is characterised by surface breakdown within a very short time period, resulting in vapour plus equilibrium liquid droplets. This means that the design of a protection system is limited by the critical temperature of its material, as increased damage will arise if explosive boiling occurs. Modelling the explosive boiling damage is thus not the focus of this paper, as the objective is to avoid the protection system reaching critical temperature. Since explosive boiling only occurs when the target reaches temperatures near the thermodynamic critical values of the material, the ablation mechanism assumed in the model is vaporization. The flow of material vaporized from the surface (ablation rate, $\mathrm{m} / \mathrm{sec}$ ) follows the Hertz-Knudsen equation [9], Equation 11.

$$
v(T)=\sqrt{\frac{m}{2 \pi k_{B} T}} \frac{P_{o}}{\rho} \exp \left(\frac{L_{v}}{R}\left(\frac{1}{T_{b}}-\frac{1}{T}\right)\right)
$$

Where $m$ is the atomic mass of the material, $T_{b}$ is the boiling temperature at the pressure $p_{o}$, $k_{B}$ the Boltzmann constant, and $L_{v}$ is the latent heat of vaporization of the material.

The heat conduction equation in a material is described in Equation 12,

$$
\rho(T) C_{p}(T) \frac{\partial T(x, y, z, t)}{\partial t}=\nabla[k(T) \nabla(T(x, y, z, t))]+R(t)
$$

where $x, y$, and $z$ are the space coordinates and $\rho, C_{p}, k$ the mass density, specific heat at constant pressure and thermal conductivity of the target material. The source term $R(t)$ represents the thermal energy absorbed by the material.

Composite material decomposing heat can be modelled using one of two techniques. The First technique is to add the latent heat to $C_{p}$ as advised by Yu Bai [10], Equation 13. 


$$
\begin{aligned}
C_{p} & =C_{p b} f_{b}+C_{p a} f_{a}+H_{s} \frac{d \alpha}{d T} \\
f_{b} & =\frac{M_{i}(1-\alpha)}{M_{i}(1-\alpha)+M_{e} \alpha} \\
f_{a} & =\frac{M_{e} \alpha}{M_{i}(1-\alpha)+M_{e} \alpha}
\end{aligned}
$$

Where $C_{p b}$ and $C_{p a}$ are the specific heat of the composite and char material; $f_{a}$ and $f_{b}$ are the volume fraction of the composite and char material respectively; $H_{s}$ is the decomposition heat and $\alpha$ is the decomposition degree; $M_{i}$ is the initial mass of composite material $\left(\rho_{0}\right.$.Volume) and $M_{e}$ is the final mass of composite material $\left(M_{i \cdot} \cdot f_{f 0}\right) ; f_{f 0}$ is the initial composite material fibre volume fraction.

The second technique is to rewrite the heat conduction equation, Equation 14,

$$
\rho(T) C_{p}(T) \frac{\partial T(x, y, z, t)}{\partial t}=\nabla[k(T) \nabla(T(x, y, z, t))]+Q(t)-\rho H_{s} \frac{\partial \alpha}{\partial t}
$$

Then use the heatval user material subroutine (available in ABAQUS) to model the decomposition kinetics and heat during the lightning strike event. Decomposition heat is negative energy, which is consumed by the kinetic reaction. Damage in composite material can be reduced by increasing the value of decomposition heat. Commonly, the epoxy decomposition can be simulated by modelling the pyrolysis behaviour of the composite, which can be estimated using thermogravimetric analyser.

The experimental results reported by Ogasawara etc. [4] are summarized in Equation 15,

$$
\frac{d \alpha}{d t}=A \exp (-Q / R T)(1-\alpha)^{n}
$$

where $\mathrm{R}$ is the universal gas constant $(\mathrm{R}=8.31 \mathrm{~J} / \mathrm{mol} / \mathrm{K})$. The estimated parameters where $\mathrm{n}$ $=3.5, \mathrm{~A}=5.0 \times 10^{13}(1 / \mathrm{min})$, and $\mathrm{Q}=180 \mathrm{~kJ} / \mathrm{mol} / \mathrm{K}$. The heating rates applied during the experimental setup where of $2.5{ }^{\circ} \mathrm{C}, 10{ }^{\circ} \mathrm{C}$, or $20{ }^{\circ} \mathrm{C} / \mathrm{min}$. The onset of weight decreased around $300{ }^{\circ} \mathrm{C}$ and the weight was saturated approximately at $500{ }^{\circ} \mathrm{C}$.

Using Equation 15 to model the decomposition rate is not appropriate, as the heating rate under lightning strike conditions is much higher than the experimental applied heating rate.

\subsection{Numerical model}

The experimental composite panel specimen is made of carbon fiber/epoxy (IM600/133), with a 32-ply quasi-isotropic layup ([45\% $\left.\left./ 0^{\circ} /-45^{\circ} / 90^{\circ}\right]_{4 \mathrm{~S}}\right)$. The thickness of each ply is 0.147 $\mathrm{mm}$, resulting in a total panel specimen thickness of $4.7 \mathrm{~mm}$. The specimen is $300 \times 300 \mathrm{~mm}$. Material thermal/Electrical properties, such as thermal conductivity, specific heat, and sublimation heat are defined in Table 2. The composite panel is divided into two partitions. One partition represents the region under the lightning strike conducting channel. The second partition represents the remaining part of the composite specimen. The latent decomposition heat of the fiber/epoxy material is assumed to be $4.8 \times 10^{3} \mathrm{KJ} / \mathrm{Kg}$, which is released between $300{ }^{\circ} \mathrm{C}$ and $500{ }^{\circ} \mathrm{C}$. A linear rate of decomposition is assumed in the decomposition temperature range. The latent sublimation heat, which is released at sublimation temperature 
of $3,316{ }^{\circ} \mathrm{C}$, is assumed to be $43 \times 10^{3} \mathrm{KJ} / \mathrm{Kg}$. The last two rows in Table 2 are the assumed thermal/electrical properties of the ablated gas, which will be used in the simulations to represent regions of the experimental specimen once ablation has occurred. The electric properties of any ablated regions under the lightning conducting channel will be defined to have high conduction property in the depth direction. In the simulation this thus allows the electric charge to move to the next layer into the specimen once the preceding layer has been ablated.

Ogasawara etc. [4] did not include in their lightning strike simulations the thermal conductance between composite laminates. Thermal conductance has been measured experimentally [13] and found at room temperature to be of the order of $500 \mathrm{~W} / \mathrm{m}^{2}{ }^{\circ} \mathrm{K}$. As the epoxy thermal conductivity is reduced by $30 \%$ after it is decomposed, the thermal conductance is also reduced by the same percentage. To date there is no available published data for the electric conductance between composite laminates and thus it is assumed to be very high $\left(1 \mathrm{E} 5 \mathrm{~W} / \mathrm{m}^{2} \mathrm{~K}\right)$ within the simulations.

A copper mesh is used in this paper as the lightning strike protection system. The copper mesh thickness is assumed to be $0.05 \mathrm{~mm}$ and to cover $24 \%$ of the specimen surface area. However, the proposed modelling technique is generic and may be applied to different protection systems, such as an aluminium mesh or paint. The function of the copper mesh is to conduct the lightning strike electric charge quickly and protect the underneath composite material from damage. It is assumed that the copper will heat up, according to its specific heat property until it reaches its melting temperature point $\left(1,083{ }^{\circ} \mathrm{C}\right)$ and it consumes the heat of fusion $\left(2.05 \times 10^{5} \mathrm{~J} / \mathrm{Kg}\right)$. Above this temperature the copper will heat up until it reaches its boiling point $\left(2,567{ }^{\circ} \mathrm{C}\right)$ and will start consuming its heat of evaporation $(4.8 \mathrm{E} 6 \mathrm{~J} / \mathrm{Kg})$ as it evaporates. Heating up and evaporation of the copper is stopped by whichever of the following two mechanisms; total ablation of the copper mesh or explosive boiling of the copper mesh as it reaches its critical temperature $\left(8,000{ }^{\circ} \mathrm{C}\right)$. As noted before the damage effect of explosive boiling is not modelled in this paper and the critical temperature is used as a simulation threshold.

The modelled copper thermal/electrical properties are listed in Table 3. The copper thermal performance is simulated in ABAQUS using a user material subroutine UMATHT, which defines the thermal constitutive behaviour of the material as well as internal heat generation during the heat transfer processes. It must define the internal energy per unit mass and its variation with respect to temperature and to spatial gradients of temperature, and the heat flux vector and its variation with respect to temperature and to gradients of temperature.

The material subroutine calculation steps are:

Step-1. Calculate the material specific heat due to latent heat (melting, evaporation).

$$
C_{P}=\frac{H_{L}}{\Delta T_{m}}+\frac{C_{p s}+C_{p l}}{2}
$$

where $\mathrm{H}_{\mathrm{L}}$ is material latent heat (melting, evaporation), $\mathrm{C}_{\mathrm{ps}}$ is material specific heat at solidus temperature, $\mathrm{C}_{\mathrm{pl}}$ is material specific heat at liquids temperature, and $\Delta \mathrm{T}_{\mathrm{m}}$ is the difference between liquids and solidus temperatures.

Step-2. Calculate the change in internal energy due to heat conduction, 


$$
\begin{aligned}
& \Delta U_{c}=\frac{\Delta U}{\Delta T} \Delta T \\
& \frac{\Delta U}{\Delta T}=C_{P}
\end{aligned}
$$

Step-3. Calculate the change in internal energy due to joule heat effect,

$$
\Delta U_{e}=\mu \cdot P_{e c} \cdot(1 / \rho)
$$

Where $\mu$ is the joule heat factor $(0.92), \mathrm{P}_{\mathrm{ec}}$ is dissipated electrical energy, and $\rho$ is material density.

Step-4. Check material ablation using Equation(11), and explosive boiling temperature.

Step-5. Calculate total change in internal energy, $\Delta \mathrm{U}_{\mathrm{t}}=\Delta \mathrm{U}_{\mathrm{c}}+\Delta \mathrm{U}_{\mathrm{e}}$.

The simulation boundary conditions where defined to match as closely as possible the experimental setup of Ogasawara etc. [4]. Thus the electrical potential at the bottom of the specimen was assumed to be zero, as a conducting copper plate under the bottom of the specimen was electrically grounded in the experimental setup, Figure 2. The electrical potential at the side surfaces was also assumed as zero, because electrical discharge from the side surfaces to the bottom copper plate was observed during all of the impulse tests [4]. Thermal radiation was given for the upper and side surfaces of the specimen, whereas the bottom surface was assumed adiabatic. Although it was understood that the heat transfer to the copper plate at the bottom surface should be examined, initial analysis indicated that the temperature increment at the bottom of the specimen was almost zero. It was therefore ignored. The emissivity and environment temperature were modelled as 0.9 and $25{ }^{\circ} \mathrm{C}$, respectively.

Ogasawara etc. [4] applied the electrical charge at the centre node of the composite plate using a concentrated electric charge time profile. This type of load application is appropriate only for electromagnetic analysis, but not for structural analysis. Applying the electric load at a single one node makes the temperature profile at this node and the surrounding area dependent on the mesh density of the finite element model. Increasing the number of elements around the panel centre leads to increase in temperature profile. Ogasawara etc. [4] thus ignored the size of lightning bolt, which range from $1-10 \mathrm{~mm}$ in diameter [7], which will significant influence predicted results. Modelling a realistic electric channel will eliminate local modelling issues and makes it possible to use a quarter model of the specimen, Figure 3 and 4 . Thus a $10 \mathrm{~mm}$ diameter conducting electrical channel is assumed for the herein simulations.

Each lamina of the composite laminate is meshed using an eight-node isoperimetric solid element to the plane of symmetry of the composite panel in the top half of the specimen, Figure 3. Orthotropic material properties calculated using the rule of mixtures is used for the elements in the bottom half of the composite panel. The full detail of the copper mesh geometry is modelled at the specimen centre $(50 \times 50 \mathrm{~mm})$ but idealised elsewhere in the model using averaged properties, Figure 4. The copper mesh is meshed with 8,503 DC3D8E elements [ABAQUS ref]. Each of the 16 top laminas is meshed with 437 DC3D8E elements [ABAQUS ref], while the bottom 16 average laminas are modelled using DC3D8E elements. Total number of simulation elements is 13,972 . 


\subsection{Results and discussion}

Two simulation predictions are presented, the first for the specimen without the copper mesh protection system, allowing comparison with the preceding published literature, and the second with the copper mesh protection system, allowing comparison of thermal damage with and without the protection system.

\subsection{Numerical results without protection system}

The simulation predicts thermal damage up to the $5^{\text {th }}$ ply $(0.73 \mathrm{~mm})$, Figure 5 . The experimental results, Figure 6, show recession up to $0.6 \mathrm{~mm}$, which agrees well with the simulation results. Experimentally the recession is primarily due to epoxy decomposition, which leaves a mix of fibres and carbon. The applied load (peak of $40 \mathrm{kA}$ ) and the modelled conducting electric channel (diameter of $10 \mathrm{~mm}$ ) does not result in fibre ablation as peak fibre temperature is below 3,316 $\mathrm{C}^{\circ}$. Here it is worth noting that Ogasawara etc. [4] use of an unrealistic electric load application (single node) caused unrealistic simulation temperatures $\left(>10 \times 10^{4} \mathrm{C}^{\mathrm{o}}\right.$ ), which he attempted to correct for by adding an artificial electric conduction along the depth direction. The inclusion of artificial electric conductivity is necessary only to simulate the ablation mechanism of each lamina and the application of the electric current load to the next lamina, which is not necessary with the herein proposed modelling method. The temperature profile of the top lamina at the end of step- 1 is shown in Figure 7 . The temperature is cooler at the lamina centre, as the electric potential gradient is higher in the inplane direction of the lamina than the through thickness direction, as shown in Figure 8. Thus dissipated electric energy (Equation 8) is higher further from the strike centre. This is due to the lower electric conductivity in the through thickness direction and electric conductance between laminates. Thus the electric current follows the easier path along the lamina fibre directions (the top lamina is a $45^{\circ}$ lamina). The maximum temperature achieved is $2,588 \mathrm{C}^{\circ}$, and the average temperature in the area in contact with the lightning strike conducting channel is $550 \mathrm{C}^{\mathrm{o}}$, thus the epoxy is fully decomposed but the lamina is not ablated.

The temperature profile of the top lamina at the end of Step-2 is shown in Figure 9-a, while the decomposition degree is shown in Figure 9-b. The decomposition is defined in the range 0 to 1 , where 0 represents pristine composite material and 1 represents fully decomposed resin material with properties which are a mix of resin char and carbon fibres. The heat energy coming from dissipated electric energy is transferred along the top lamina fibres, in the $45^{\circ}$ direction. Assuming the damage threshold is defined by a decomposition degree higher than 0.3 the predicted damage area is approximately $16 \times 16 \mathrm{~mm}$. Thus for the top lamina the damaged area is almost similar to the loaded area. Assuming the same decomposition threshold the predicted decomposition area for the $2^{\text {nd }}$ lamina is of a maximum width of 40 $\mathrm{mm}$. Using this assumption the prediction agrees well with the experimental results [4] shown in Figure 6. The lightning current strikes the top lamina, which decomposes with time and the local electrical/thermal material properties change from pristine properties to a mix of char and carbon fibre properties. Char has a higher electric conductivity, which results in increased conductivity in the depth direction. The electric current thus reaches the $2^{\text {nd }}$ lamina which has $0^{\circ}$ degree fibres. This lamina conducts the electric charge in its fibre direction and conducts thermal heat from the top lamina; this accelerates the decomposition along the $0^{\circ}$ direction and produces the results shown in Figures 6 and 9.

Top views of the decomposition degree profile in the $2^{\text {nd }}, 3^{\text {rd }}, 4^{\text {th }}$, and $5^{\text {th }}$ laminas are shown in Figure 11. Damage size is approximately $(40 \times 12 \mathrm{~mm})$ in $2^{\text {nd }}$ lamina, $(22 \times 22 \mathrm{~mm})$ in the $3^{\text {rd }}$ lamina, $(6 \times 30 \mathrm{~mm})$ in the $4^{\text {th }}$ lamina and $(6 \times 6 \mathrm{~mm})$ in the $5^{\text {th }}$ lamina. The damage area is clearly a function of the thermal conductivity of each lamina and thermal conductance 
between adjacent laminates. The temperature profile of 5 different locations along the panel centreline is shown in Figure 12. Visible in Figure 12 are temperatures ranging from 300 to $400 \mathrm{C}^{\circ}$. As a result the resin is locally decomposed resulting in char thermal/electrical properties. Char, which has higher specific heat and convection boundary condition to air, will thus not cool is quickly as pristine composite.

In this case modelling char material properties after decomposition enables the prediction of realistic material damage. Also, by using an increased electric conductivity for the char material in the depth direction, to simulate the shift of the conducting electric channel, allows the model to efficiently represent the complex electrical loading during lightning strike. Thus the following section presents simulation predictions for the same specimen but with a surface copper mesh protection lamina.

\subsection{Numerical results with protection system}

The function of the protecting copper mesh is to conduct rapidly the electric charge away from the lightning strike zone, thus reducing the damage applied on the composite panel. Copper conducts electric charge which heats it up to the melting point $\left(1,083 \mathrm{C}^{\mathrm{o}}\right)$, then up to the evaporation temperature $\left(2,567 \mathrm{C}^{\circ}\right)$, where it starts ablation. The damage mechanism for the composite material is thus controlled by the conducting heat with the copper, which is defined by the thermal conductance between copper mesh and composite material. Two Figures are now discussed to investigate the behaviour of the copper mesh under lightning strike at two different locations. Figure 13 shows the temperature profile and ablation at a point $7 \mathrm{~mm}$ from the centre of the lightning strike. The ablation is not fast enough to stop the copper from heating to its critical temperature $\left(8,000 \mathrm{C}^{\mathrm{o}}\right)$. This means the copper in the area of the lightning strike heats up to the explosive boiling state and may cause more damage to the composite panel. The effect of explosive boiling damage is not modelled, assuming it is a critical point that has to be avoided in designing a protection system. Figure 14 shows the temperature profile and ablation at a point on the copper mesh at a distance $14 \mathrm{~mm}$ from the centre of the lightning strike. Here the ablation of the material is controlled by the heat conduction in the copper mesh and ablation occurs faster. The thickness of the copper mesh is fully ablated at a temperature of 2,616 $\mathrm{C}^{0}$. The fast ablation of the copper mesh at lower temperature means less composite damage due to heat conduction. The slower ablation in the area of the electric strike will lead to greater local damage and could be reduced by reducing the factor of thermal conductance between the copper mesh and the adjacent composite lamina. Thus installing low thermal conducting adhesive between the copper mesh and composite panel will reduce both the heat conduction and the damaged area of the composite panel.

Excluding the impact of explosive boiling the damage to the composite material in the protected specimen is down to the $3^{\text {rd }}$ lamina, Figure 15 . The damage area is $24 \times 24 \mathrm{~mm}$ in the top lamina, $30 \times 20 \mathrm{~mm}$ in the $2^{\text {nd }}$ lamina, and $12 \times 12 \mathrm{~mm}$ in the $3^{\text {rd }}$ lamina. These results are based on the assumption that thermal conductance between the copper and the composite laminas is equivalent to the conductance between laminas. Thus the use of a copper mesh only reduced the maximum damage area by $25 \%$ for the case of a $40 \mathrm{kA}$ lightning strike on a composite panel. Two techniques can be used to reduce damaged area of composite panel; one technique is to reduce thermal conductance, and second one is to use thinner copper mesh that ablates at a reduced temperature, for example 5,500 $\mathrm{C}^{\circ}$. It is a general practice of the aerospace companies to include a Glass/Epoxy lamina in between the copper mesh and the composite panel. Two advantages can be achieved by the inclusion of Glass/Epoxy lamina. 
One advantage is to act as a thermal insulation layer between the copper mesh and the composite panel. Second advantage is that the Glass/Epoxy has two reaction heats under high thermal environment. One reaction heat of value $239 \mathrm{KJ} / \mathrm{kg}$ is consumed during decomposition of epoxy and another reaction heat between carbon and silica consumes 2,093 $\mathrm{KJ} / \mathrm{kg}$.

\subsection{Conclusions}

In summary the simulation results of the unprotected composite panel agree well with the experimental data. The simulation is capable of capturing the damage size (decomposition area), and the temperature profile in the composite panel. Introducing the copper mesh reduces damage but due to the slow ablation rate of copper near the lightning strike zone potentially unnecessary damage is caused due to the heat conduction with the adjacent composite lamina. Including a low thermal conductance adhesive between the copper mesh and the composite panel could reduce damage, emulating the behaviour further from the lightning strike where faster ablation reduces the damage area.

The material properties required to simulate lightning strike on composite material can be categorized into two categories. The first category require standard measurements such as density, electric/thermal conductivity, specific heat, and phase transformation temperature and heat for the pristine, charred and ablated composite material. The second category are more difficult to measure; properties such as the size of the conducting strike channel, thermal conductance between composite laminates, thermal conductance between the protection system and the composite panel, and ablation model parameters. Thus the proposed simulation approach may be used along with experimental data to calibrate the second category of properties, and then used to design new protection systems or used in design optimisation of existing technology.

The work in this paper is the first phase of a long research project to investigate the lightning strike problem on composite structures. The protection system once evaporated will produce different plasma that are ionized and interact with the plasma of the lightning arc. Modelling the plasma of the arc was investigated by Chemartin, etc [5], however lightning and plasma interaction has not been investigated. The contribution of overpressure and magnetic forces has to be investigated. Magnetic forces are a major part of damage for metallic structures, yet it is limited to the conducting protection system for composite panels. The thickness of the protection system is small compared to the total thickness of the full composite panel, and thus the influence of magnetic forces may potentially be ignored? Estimating the overpressure contribution requires a special set of experimental data, which will capture the displacement of the zone under lightning strike as a function of time. Then, a mechanical FE module may be integrated to the developed simulations to estimate the displacement beneath a lightning strike event due to thermal strains and ablation. Thus the displacement due to overpressure that is measured experimentally and the displacement due to thermal strains and ablation that is estimated numerically can be compared and the contribution distribution defined.

\subsection{References}

[1] S.J. Haigh Taylor, "Impulse effects during simulated lightning attachments to lightweight composite panels, Int. Aerospace and Ground Conf. on Lightning and Static 
Electricity, (Paris, 2007).

[2] P.N. Gineste, R. Clerc, C. Castanie, H. Andreu, E. Buzaud, "Assessment of lightning direct effects damages by modelling techniques", Int. Aerospace and Ground Conf. on Lightning and Static Electricity, (Pittsfield, 2009).

[3] B. Lepetit, C. Escure, S. Guinard, I. Revel, G. Peres, "Thermo-mechanical effects induced by lightning on carbon fiber composite materials", Int. Aerospace and Ground Conf. on Lightning and Static Electricity, (Pars, 2011).

[4] T. Ogasawara, Y. Hirano, A. Yoshimura, "Coupled thermal-electrical analysis for carbon fiber/epoxy composites exposed to simulated lightning current", Composites: Part A, 41 p973-981 (2010).

[5] L. Chemartin, P. Lalande, B. Peyrou, A. Chazottes, P.Q. Elias, "Direct Effects of Lightning on Aircraft Structure: Analysis of the Thermal, Electrical and Mechanical Constraints", Journal of Aerospace Lab, Issue 5 (2012).

[6] Lightning qualification test techniques for aerospace vehicles and hardware, MIL-STD1757A, MIL, Department of Defence (1983).

[7] F. Fisher, J. Plumer, R. Perala, "Lightning Protection of Aircraft", Lightning Technologies Inc., (2004).

[8] A. Kaddani, C. Delalondre, O. Simonin, H. Minoo, "Thermal and Electrical Coupling of Arc Electrodes". High Temp. Chem. Processes Vol 3, pp.441 (1994).

[9] V. Oliveira, R. Vilar, "Finite element simulation of pulsed laser ablation of titanium carbide", 253 p 7810-7814 (2007).

[10] Y. Bai, T. Keller, T. Vallee, "Modeling of thermo-physical properties and thermal responses for FRP composites in fire", Asia-Pacific Conference on FRP in Structures (APFIS 2007).

[11] J. Fanucci, "Thermal response of radiantly heated Kevlar and graphite/epoxy composites", Journal of Composite Materials, Vol.21, p 129-139 (1987).

[12] C.A. Griffis, J.A. Nemes, F.R. Stronesifer, A.I. Chang, "Degradation in strength of laminated composites subjected to intense heating and mechanical loading", Journal of Composite Materials, Vol.20, p 216-235 (1986).

[13] S. R. Mirmira; M. C. Jackson; L. S. Fletcher, "Effective thermal conductivity and thermal contact conductance of graphite fiber composites", Journal of Thermophysics and Heat Transfer, Vol. 15, pp. 18-26 (2001).

[14] S.J. Zinkle, S.A. Fabritsiev, "Copper alloys for high heat flux structure applications", Journal of Nuclear Fusion, Vol. 5, pp. 163-181 (1994).

[15] G.R. Gathers, "Thermophysical properties of liquid copper and aluminium", Int. Journal of Thermophysics, Vol. 4, pp. 209-226 (1983).

[16] G.K. White, M.L. Minges, “Thermophysical Properties of Some Key Solids: An Update", Int. Journal of Thermophysics, Vol. 18, pp. 1269-1327 (1997). 
Table 1: Current waveform description MIL and SAE [6].

\begin{tabular}{|l|l|}
\hline High Current & $\begin{array}{l}\text { Peak current }=200 \mathrm{kA} \pm 10 \%-\text { Action integral }=2.0 \times 106 \mathrm{~A}^{2} \mathrm{sec} \\
\text { Current rate-of-rise }=1.4 \times 1011 \mathrm{~A} / \mathrm{sec} \pm 10 \%, \text { Time duration } \leq 500 \mu \mathrm{s}\end{array}$ \\
\hline $\begin{array}{l}\text { Intermediate } \\
\text { Current }\end{array}$ & Maximum Charge Transfer $=10 \mathrm{C}-$ Average Amplitude $=2 \mathrm{kA} \pm 10 \%$ \\
\hline $\begin{array}{l}\text { Continuing } \\
\text { Current }\end{array}$ & $\begin{array}{l}\text { Charge transfer }=200 \mathrm{C} \pm 20 \%-\text { Average amplitude }=400 \mathrm{~A} \\
\text { Time duration: } 0.25 \mathrm{sec} \leq \mathrm{T} \leq 1 \mathrm{sec}\end{array}$ \\
\hline Restrike Current & $\begin{array}{l}\text { Peak amplitude }=100 \mathrm{kA} \pm 10 \%-\text { Action integral }=0.25 \times 106 \mathrm{~A}^{2} \mathrm{sec} \\
\text { Time duration } \leq 500 \mu \mathrm{s}\end{array}$ \\
\hline
\end{tabular}

Table 2: Carbon fiber/epoxy thermal and electrical material properties vs. temperature [11, 12].

\begin{tabular}{|c|l|l|l|l|l|l|l|}
\hline $\begin{array}{c}\text { Temperat } \\
\text { ure }\left[{ }^{\circ} \mathrm{C}\right]\end{array}$ & $\begin{array}{l}\text { Density } \\
{[\mathrm{Kg} / \mathrm{m}} \\
\left.\mathrm{m}^{3}\right]\end{array}$ & $\begin{array}{l}\text { Specif } \\
\text { ic heat } \\
{[\mathrm{J} / \mathrm{Kg} .} \\
\left.{ }^{\mathrm{o}}\right]\end{array}$ & $\begin{array}{l}\text { Longitudi } \\
\text { nal } \\
\text { thermal } \\
\text { conductivi } \\
\text { ty } \\
{[1 / \Omega . \mathrm{mm}]}\end{array}$ & $\begin{array}{l}\text { Transvers } \\
\text { e thermal } \\
\text { conductiv } \\
\text { ity } \\
{[1 / \Omega . \mathrm{mm}]}\end{array}$ & $\begin{array}{l}\text { Longitudi } \\
\text { nal } \\
\text { electrical } \\
\text { conductivi } \\
\text { ty } \\
{[1 / \Omega . \mathrm{mm}]}\end{array}$ & $\begin{array}{l}\text { Transvers } \\
\text { electrical } \\
\text { enductiv } \\
\text { ity } \\
{[1 / \Omega . \mathrm{mm}]}\end{array}$ & $\begin{array}{l}\text { In-depth } \\
\text { electrical } \\
\text { conductiv } \\
\text { ity } \\
{[1 / \Omega . \mathrm{mm}]}\end{array}$ \\
\hline 25 & $1.52 \mathrm{E}-6$ & 1065 & 0.008 & 0.00067 & 35.97 & 0.001145 & $\begin{array}{l}3.876 \mathrm{E}- \\
006\end{array}$ \\
\hline 343 & $1.52 \mathrm{E}-6$ & 2100 & 0.002608 & 0.00018 & 35.97 & 0.001145 & $\begin{array}{l}3.876 \mathrm{E}- \\
006\end{array}$ \\
\hline 500 & $1.1 \mathrm{E}-6$ & 2100 & 0.001736 & 0.0001 & 35.97 & 2 & 2 \\
\hline 510 & $1.1 \mathrm{E}-6$ & 1700 & 0.001736 & 0.0001 & 35.97 & 2 & 2 \\
\hline 1000 & $1.1 \mathrm{E}-6$ & 1900 & 0.001736 & 0.0001 & 35.97 & 2 & 2 \\
\hline 3316 & $1.1 \mathrm{E}-6$ & 2509 & 0.001736 & 0.0001 & 35.97 & 2 & 2 \\
\hline$>3316$ & $1.1 \mathrm{E}-6$ & 5875 & 0.001015 & 0.001015 & 0.2 & 0.2 & $1 \mathrm{E}+6$ \\
\hline $\begin{array}{c}\text { (Load } \\
\text { elements) } \\
- \text { Gas }\end{array}$ & & & & & & & \\
\hline $\begin{array}{c}>3316 \\
\text { (unload } \\
\text { elements) } \\
- \text { Gas }\end{array}$ & $1.1 \mathrm{E}-6$ & 5875 & 0.001015 & 0.001015 & 0.2 & 0.2 & 0.2 \\
\hline
\end{tabular}


Table 3: Copper thermal and electrical material properties $[14,15,16]$.

\begin{tabular}{|c|c|c|c|c|}
\hline $\begin{array}{l}\text { Temperature } \\
{\left[{ }^{\circ} \mathrm{C}\right]}\end{array}$ & $\begin{array}{l}\text { Density } \\
{\left[\mathrm{Kg} / \mathrm{mm}^{3}\right]}\end{array}$ & $\begin{array}{l}\text { Specific } \\
\text { heat } \\
{[\mathrm{J} / \mathrm{Kg} .} \\
\left.{ }^{\circ} \mathrm{K}\right]\end{array}$ & $\begin{array}{l}\text { Longitudinal } \\
\text { thermal } \\
\text { conductivity } \\
{[1 / \Omega . \mathrm{mm}]}\end{array}$ & $\begin{array}{l}\text { Longitudinal } \\
\text { electrical } \\
\text { conductivity } \\
{[1 / \Omega . \mathrm{mm}]}\end{array}$ \\
\hline 25 & $8.95 \mathrm{E}-6$ & 385 & 0.401 & 58140 \\
\hline 500 & $1.1 \mathrm{E}-6$ & 431 & 0.37 & 20120 \\
\hline 510 & $1.1 \mathrm{E}-6$ & 431 & 0.339 & 4651 \\
\hline 1000 & - & 490.952 & 0.15 & 3704 \\
\hline 1700 & - & - & 0.18 & 2404 \\
\hline 2600 & - & - & - & 2227 \\
\hline 3227 & - & - & - & 1500 \\
\hline 7000 & - & - & - & - \\
\hline 7200 & - & - & - & - \\
\hline 8000 & $1.1 \mathrm{E}-6$ & 550 & 0.18 & 1400 \\
\hline
\end{tabular}

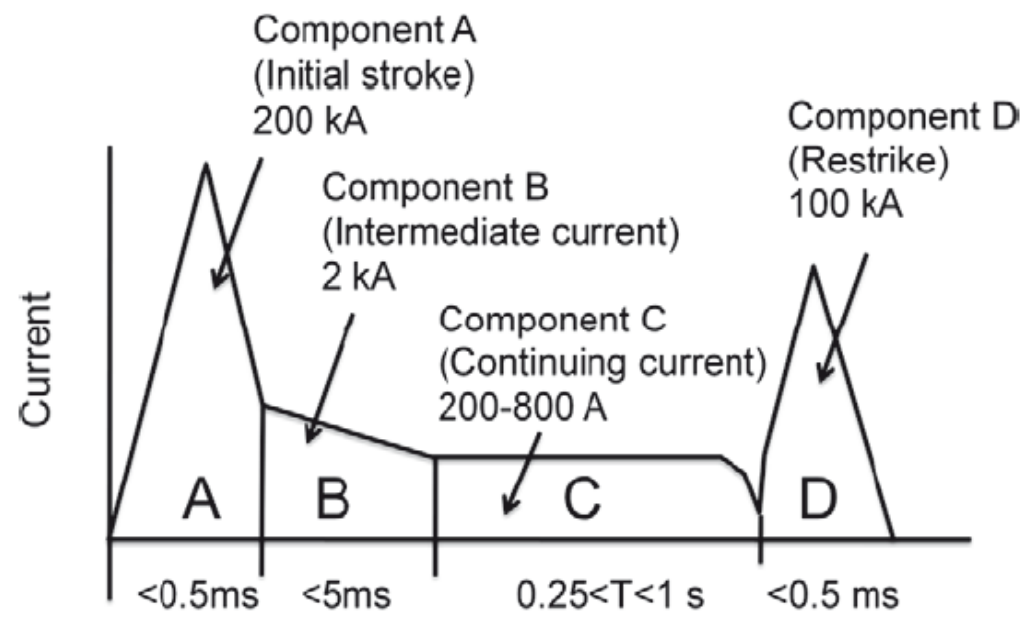

Figure 1: MIL Standard-1757A, SAE-ARP 5412.

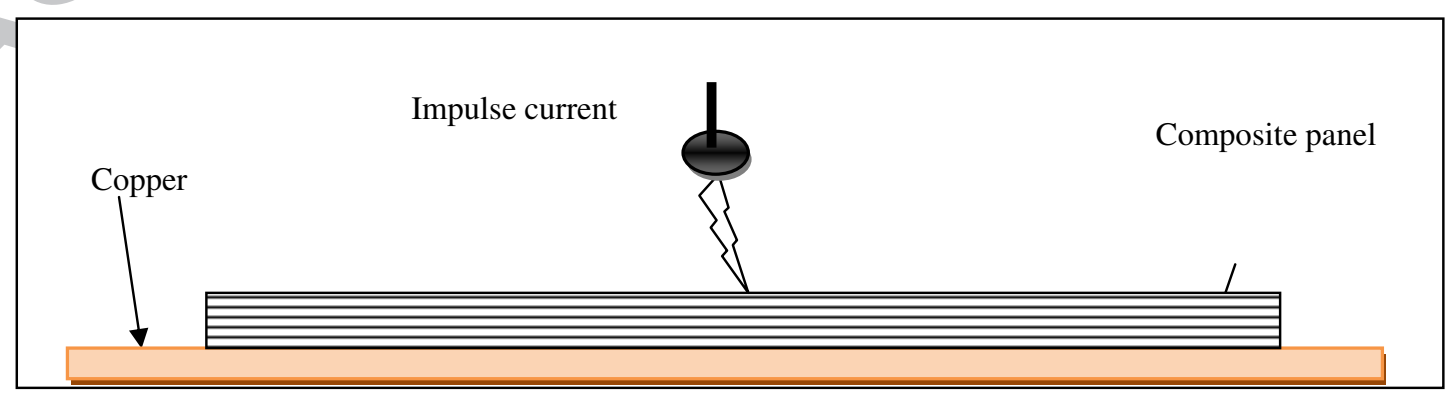

Figure 2: Test setup of composite panel under lightning strike environment. 


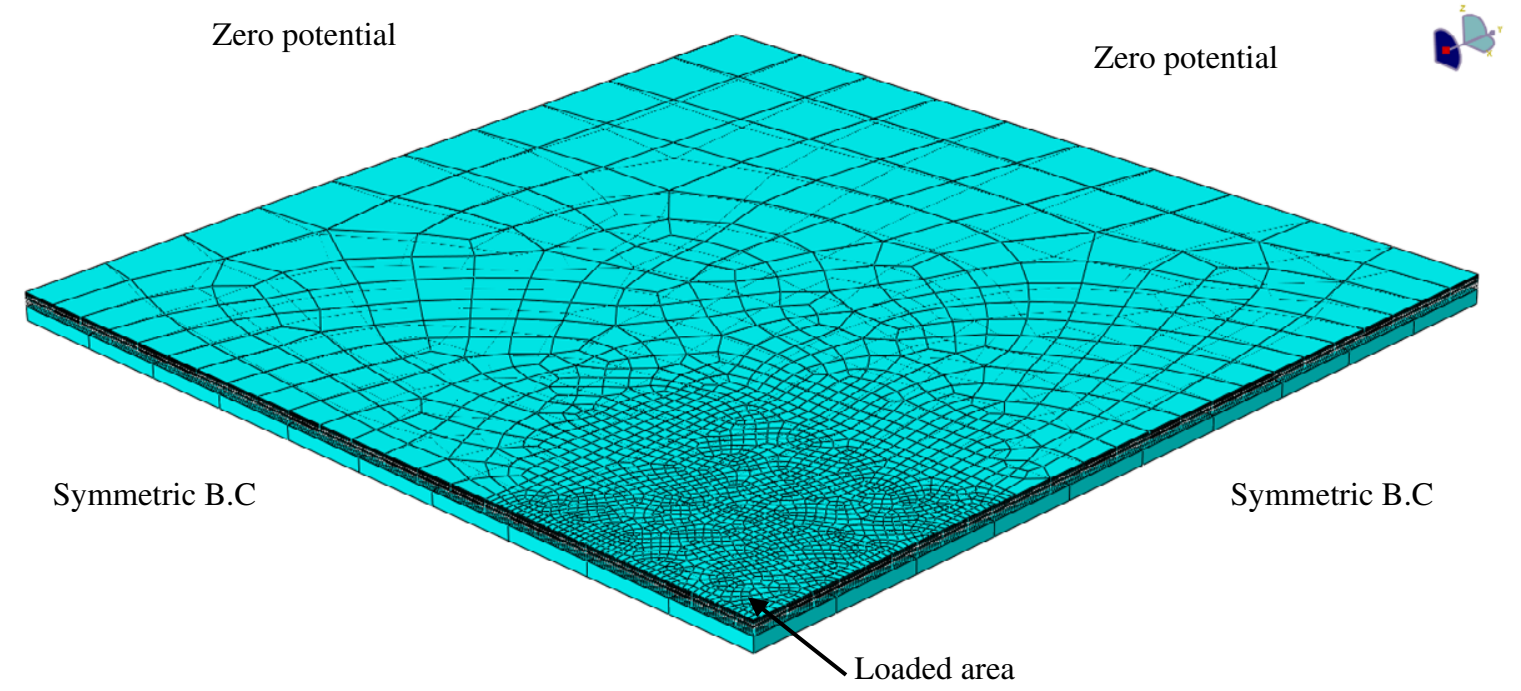

Figure 3: Unprotected meshed composite panel setup with applied boundary conditions

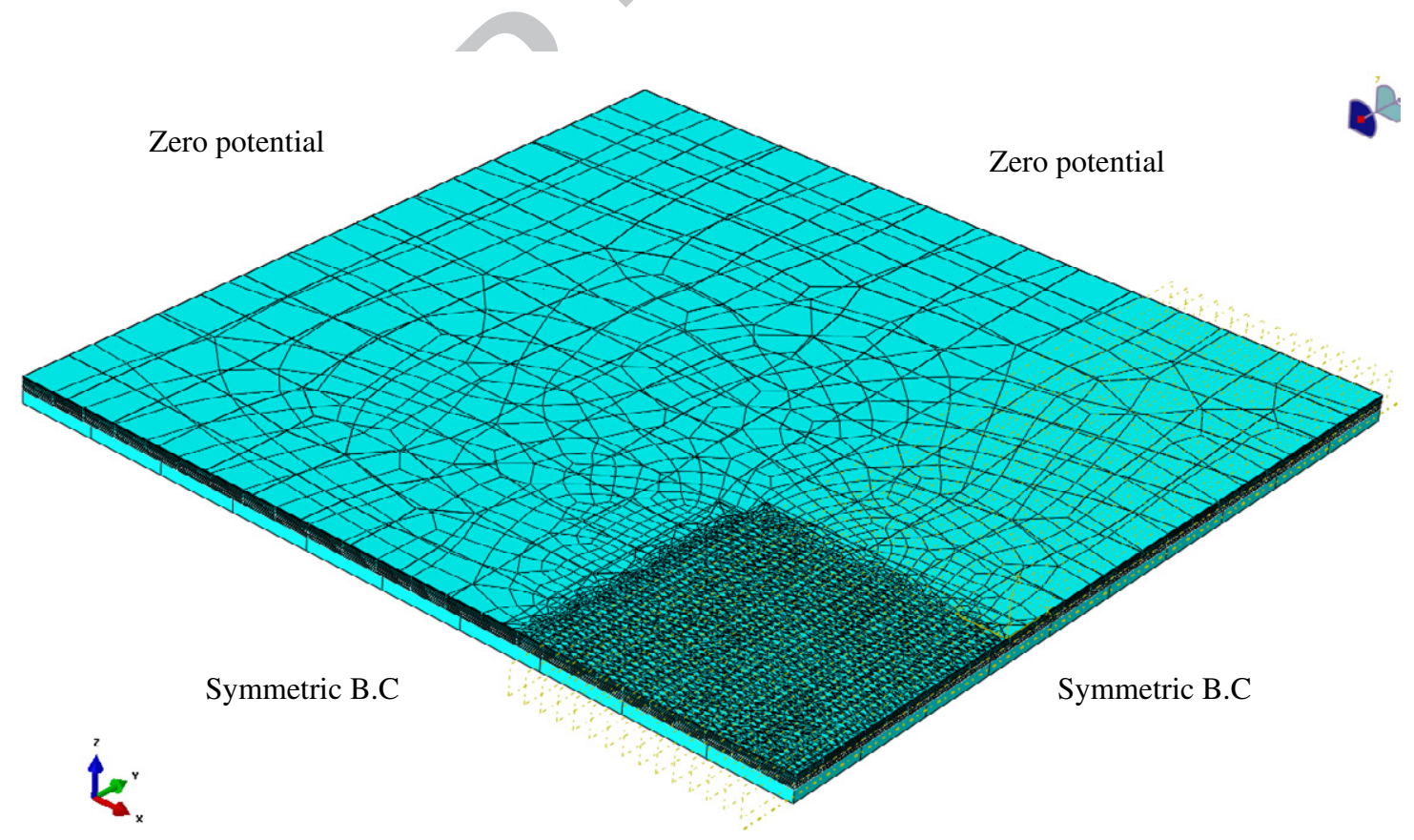

Figure 4: Protected meshed panel setup with applied boundary conditions. 


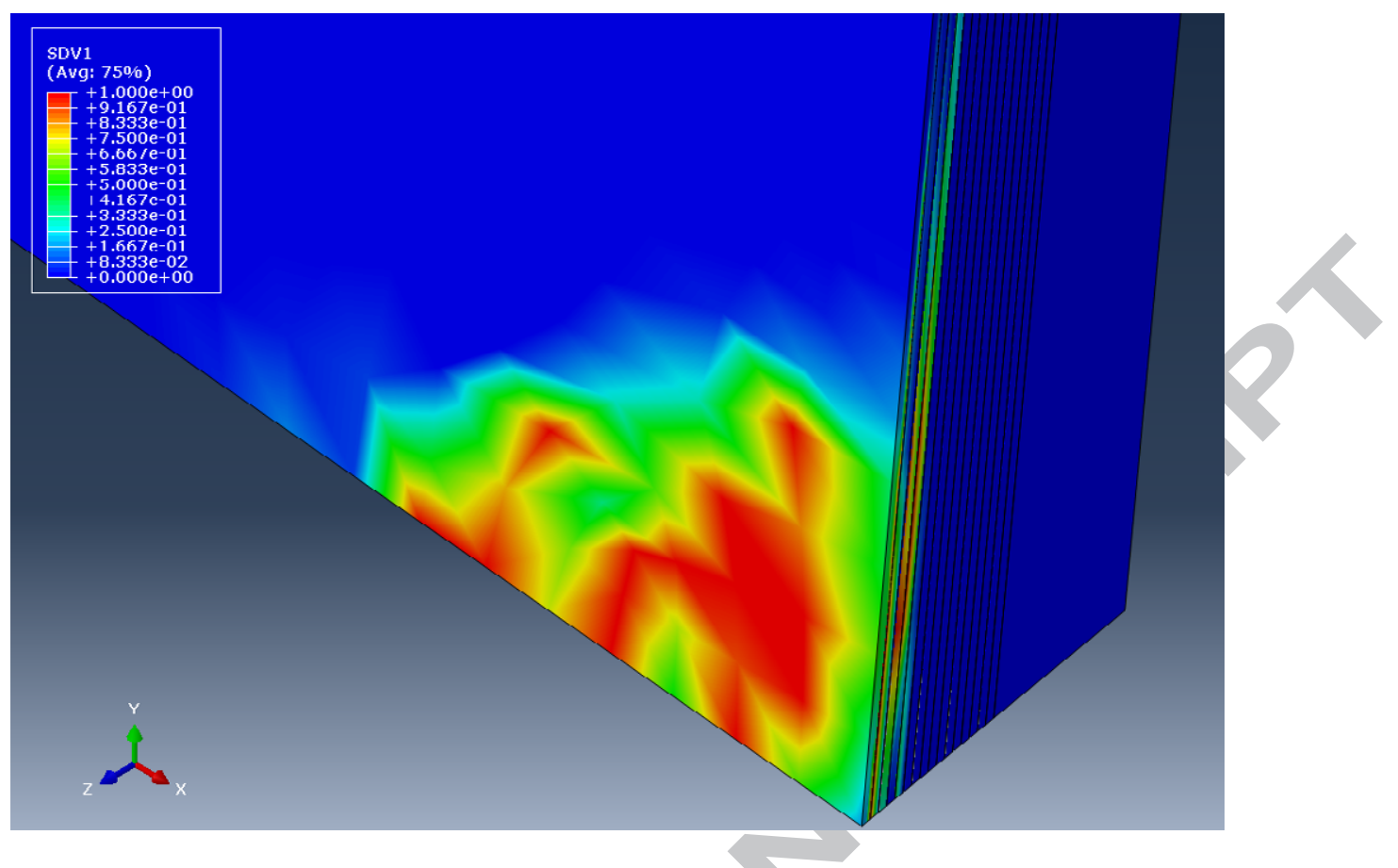

Figure 5: Decomposed laminate layout.

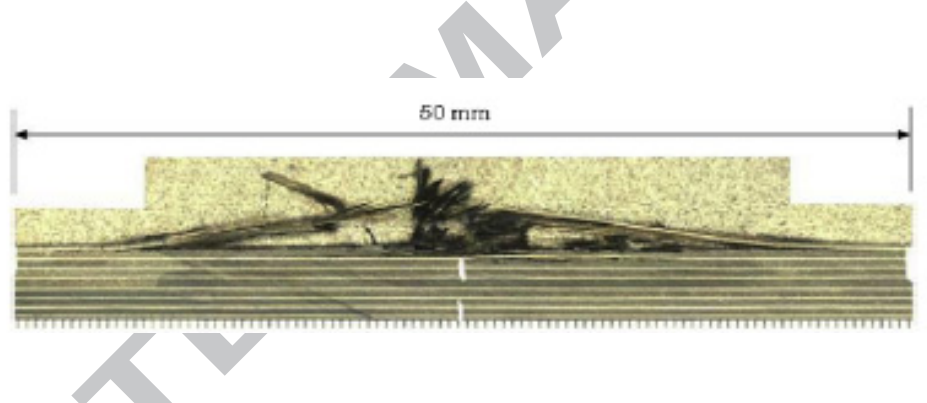

Figure 6: Cross-section of the CFRP laminates [4]. 


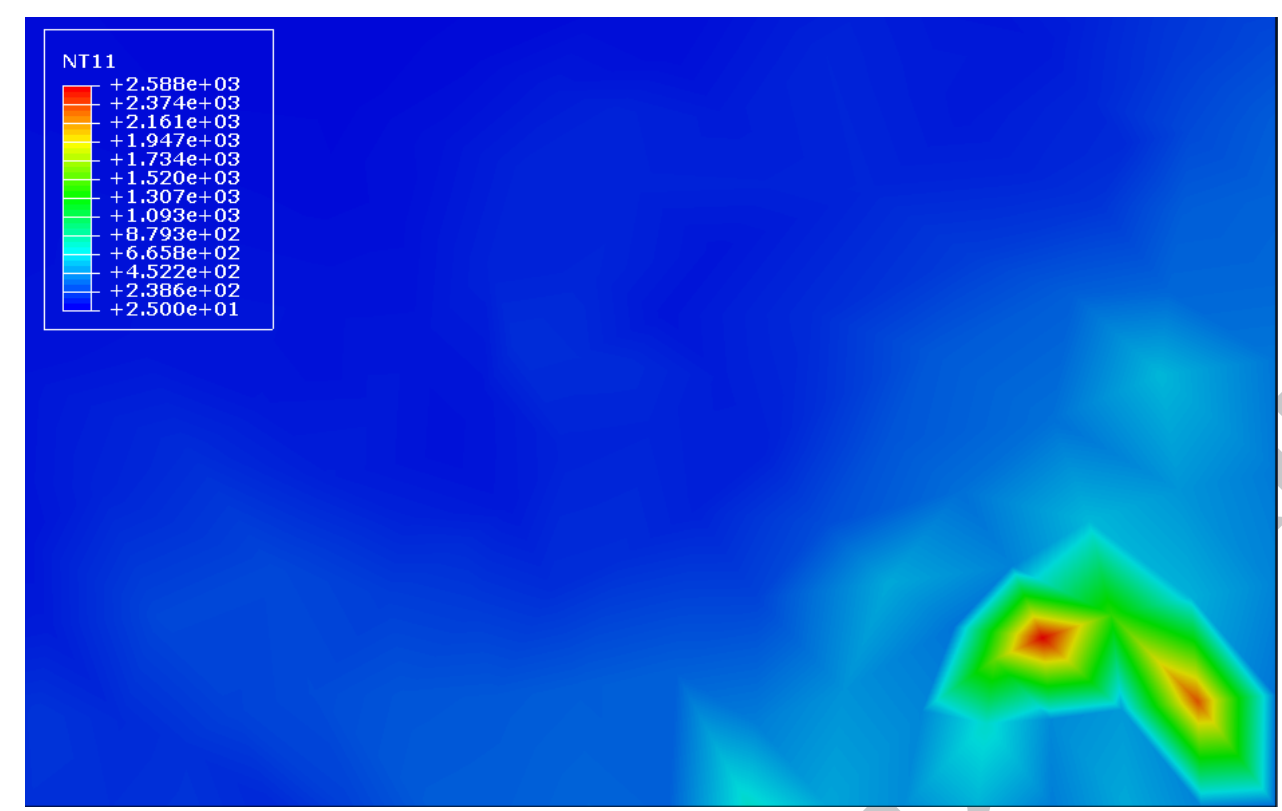

Figure 7: Top lamina temperature distribution at end step-1.

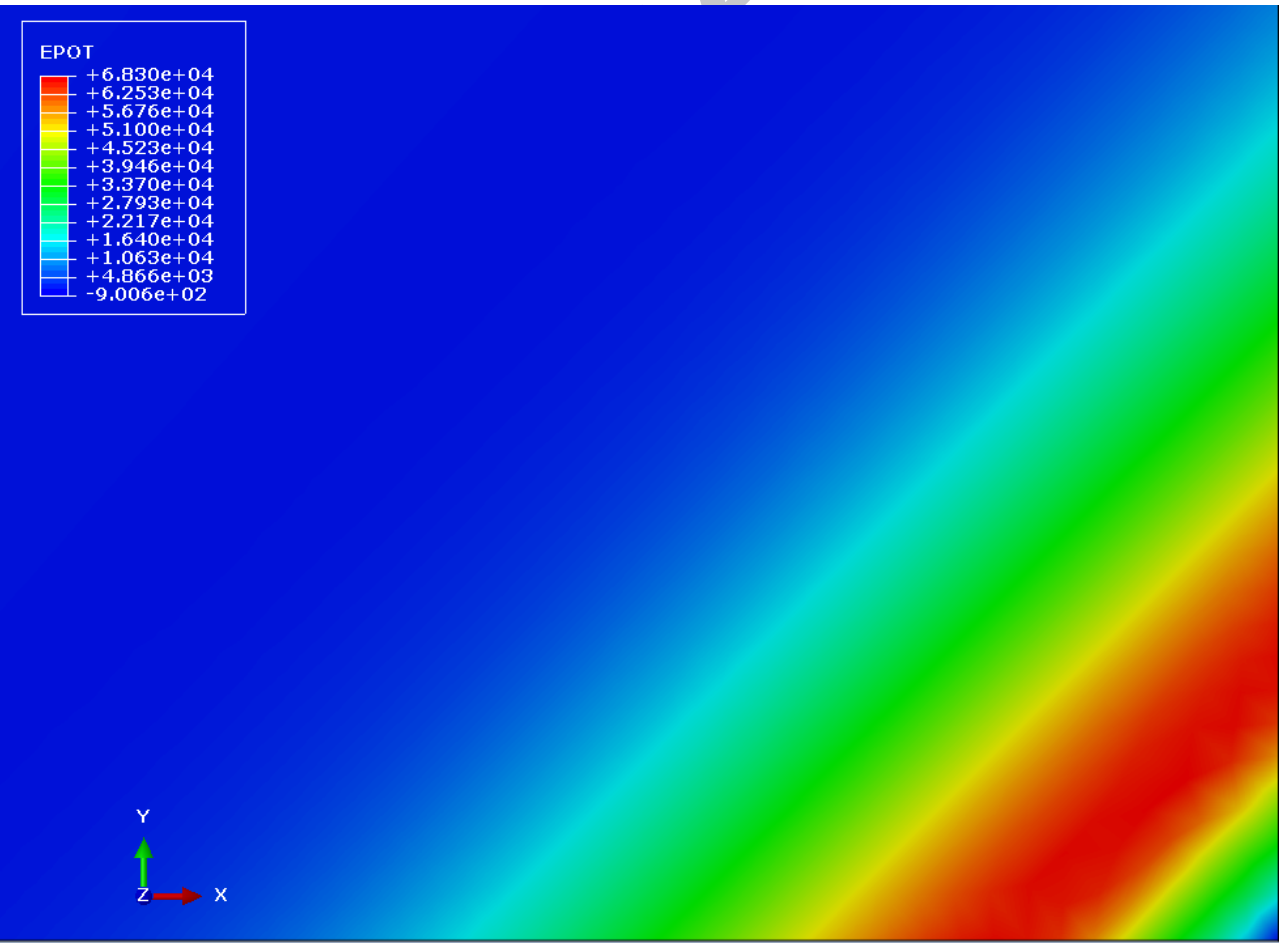

Figure 8: Electric potential gradient for top lamina. 


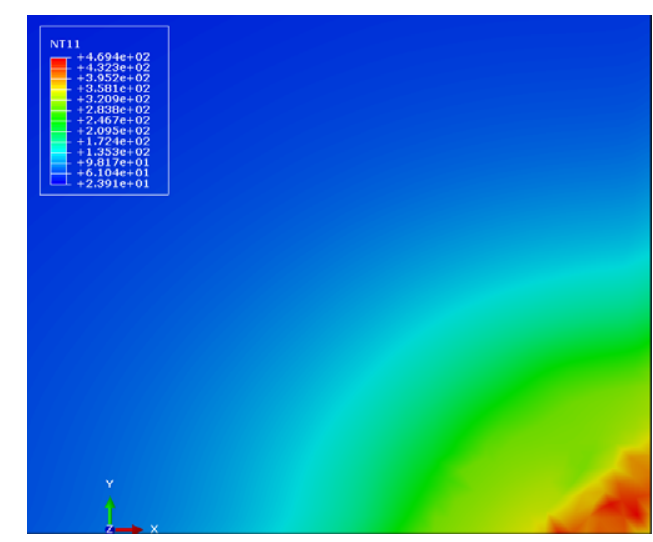

(a)

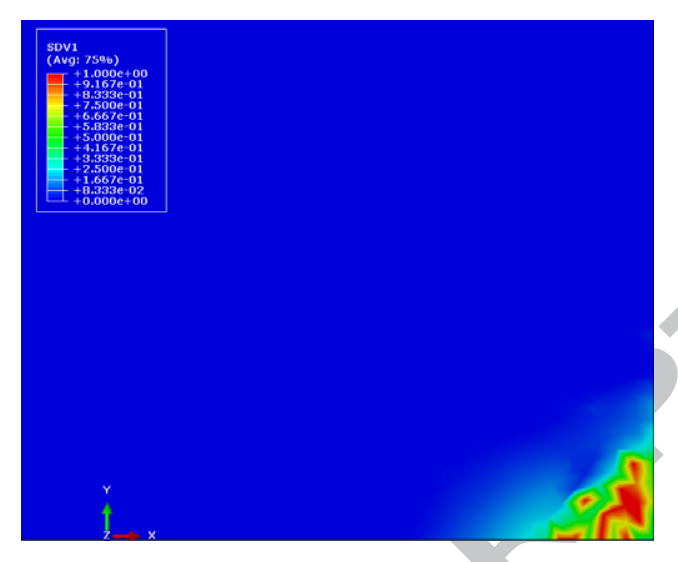

(b)

Figure 9: Top lamina temperature profile and decomposition degree at end of Step-2.

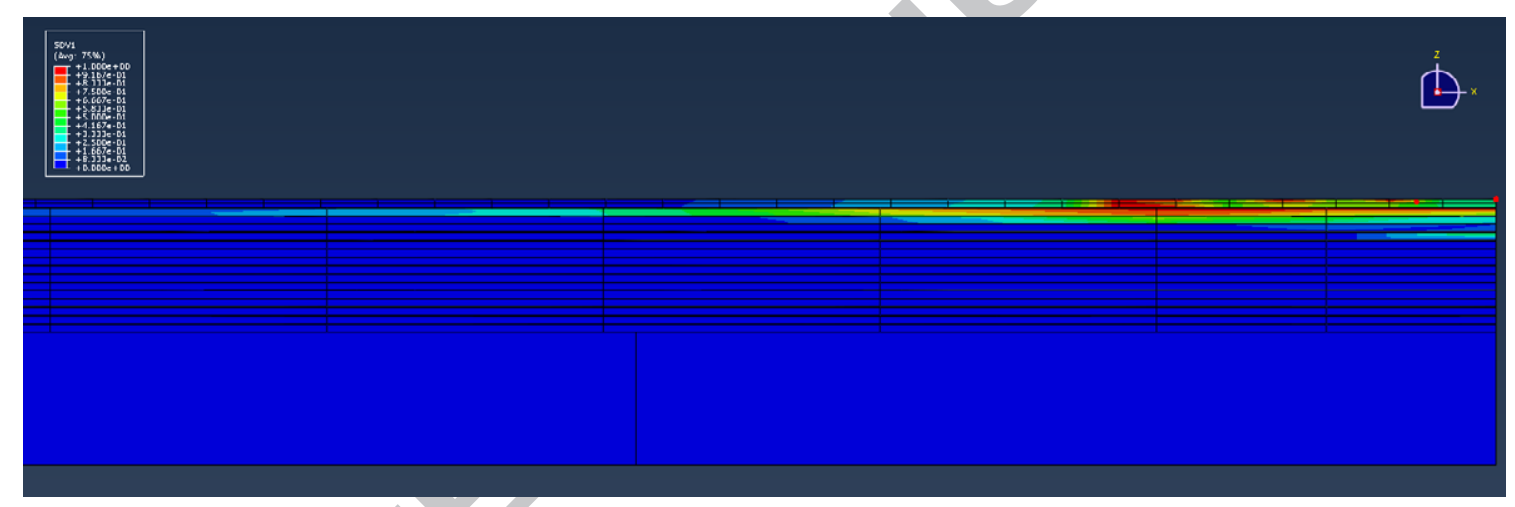

Figure 10: Side view of decomposition degree profile.

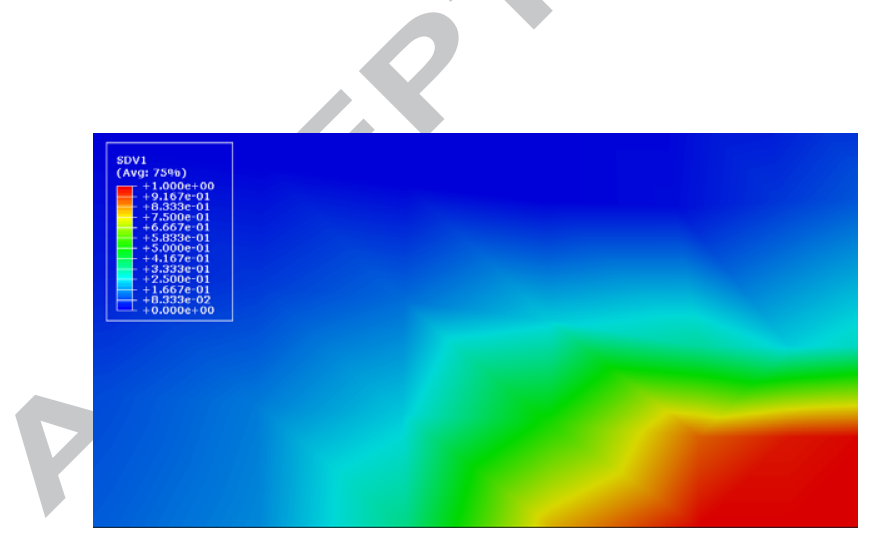

(a)

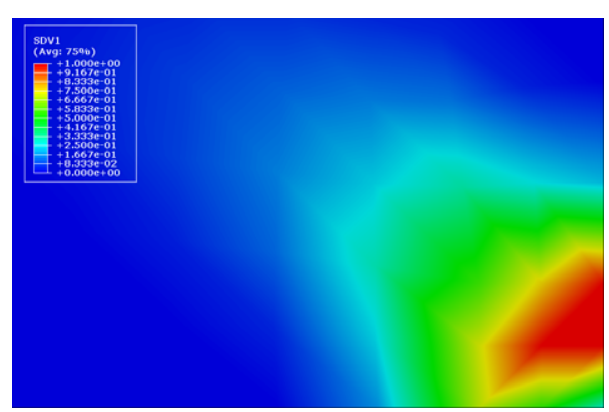

(b) 


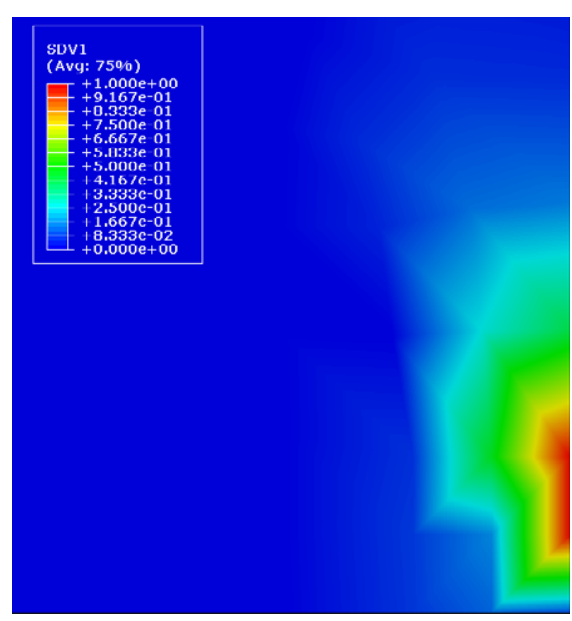

(c)

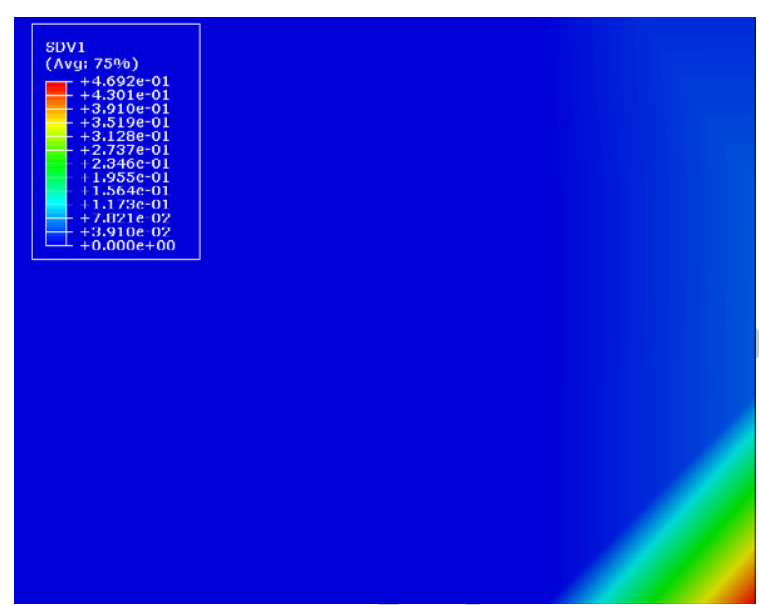

(d)

Figure 11: Decomposition degree profile for $2^{\text {nd }}, 3^{\text {rd }}, 4^{\text {th }}$, and $5^{\text {th }}$ layer respectively.
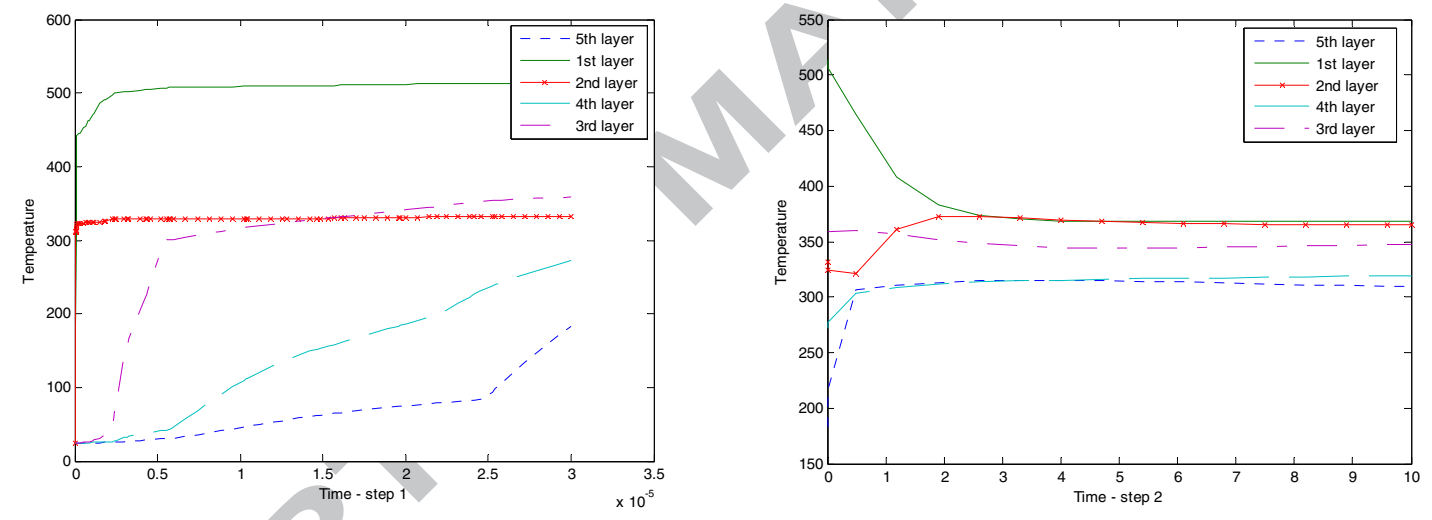

Figure 12: Temperature profile for up to 5 nodes on centreline along the depth direction.

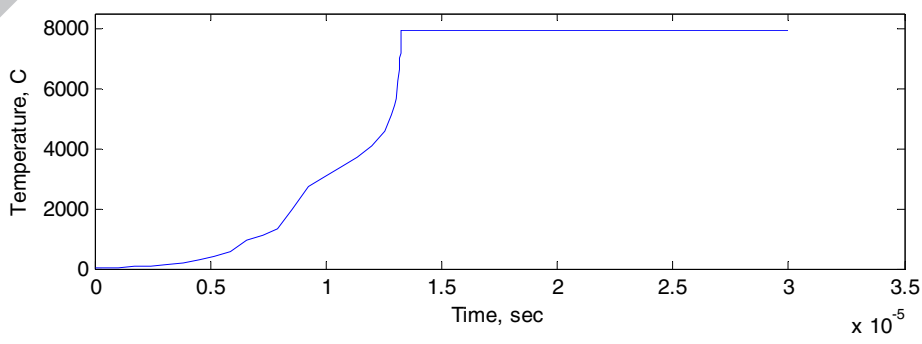

(a) 


\section{ACCEPTED MANUSCRIPT}

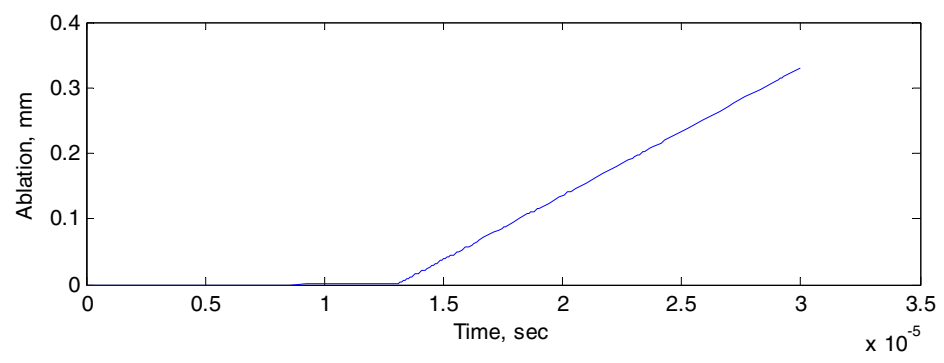

(b)

Figure 13: Temperature profile and ablation on copper mesh near loading area.
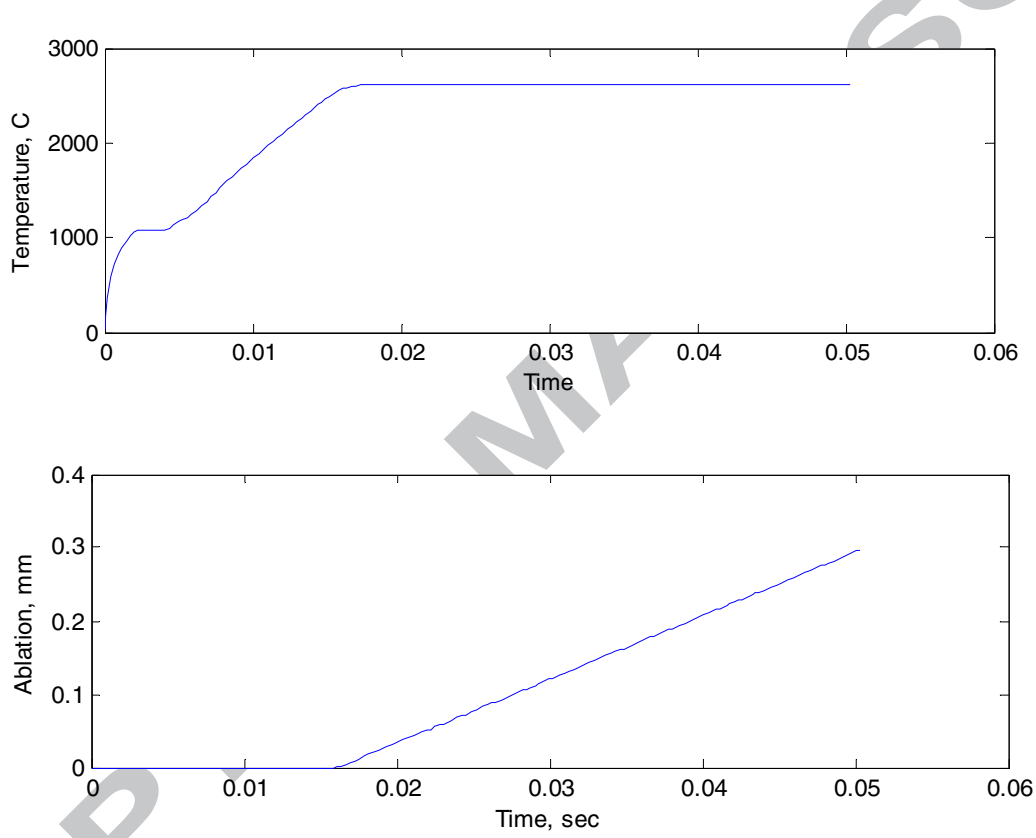

Figure 14: Temperature profile and ablation on copper mesh further from loading area. 


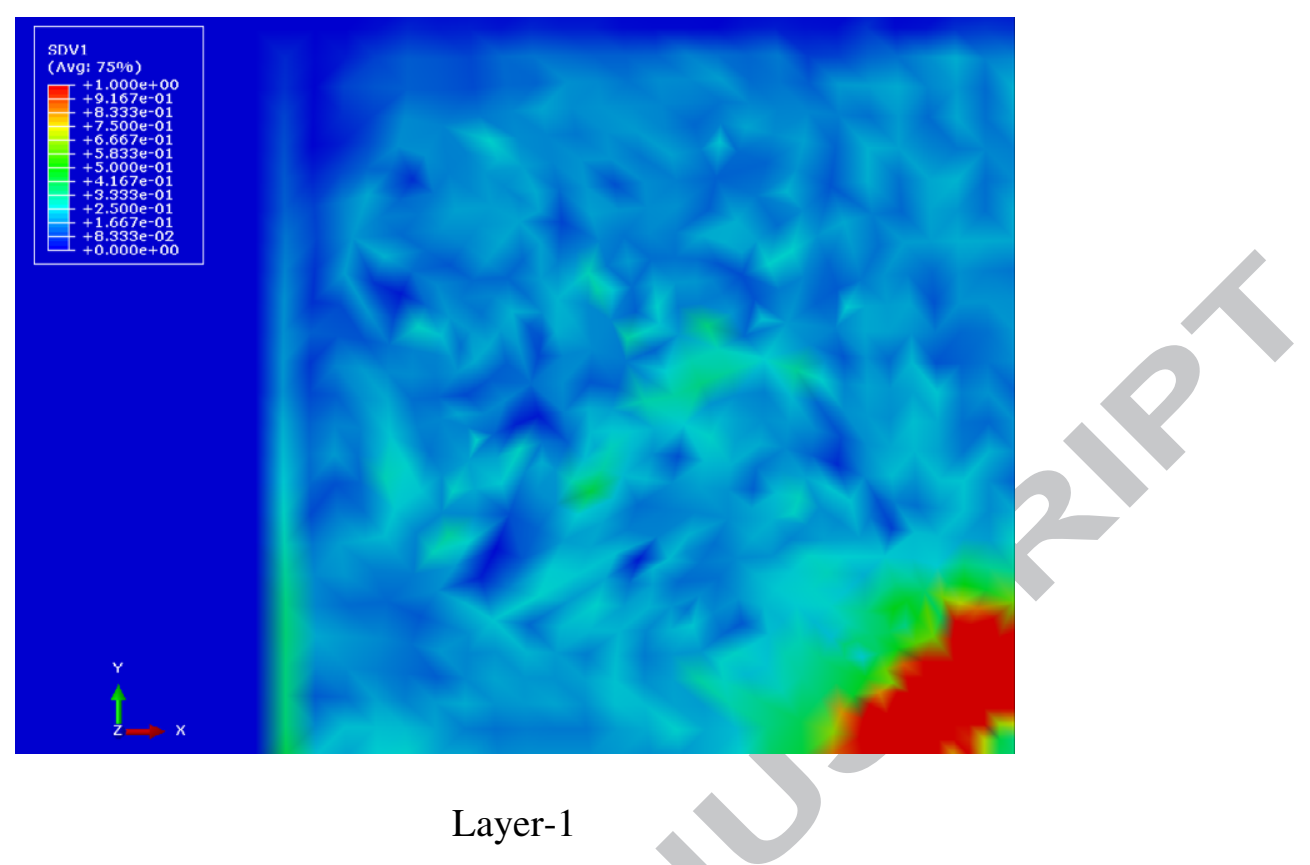

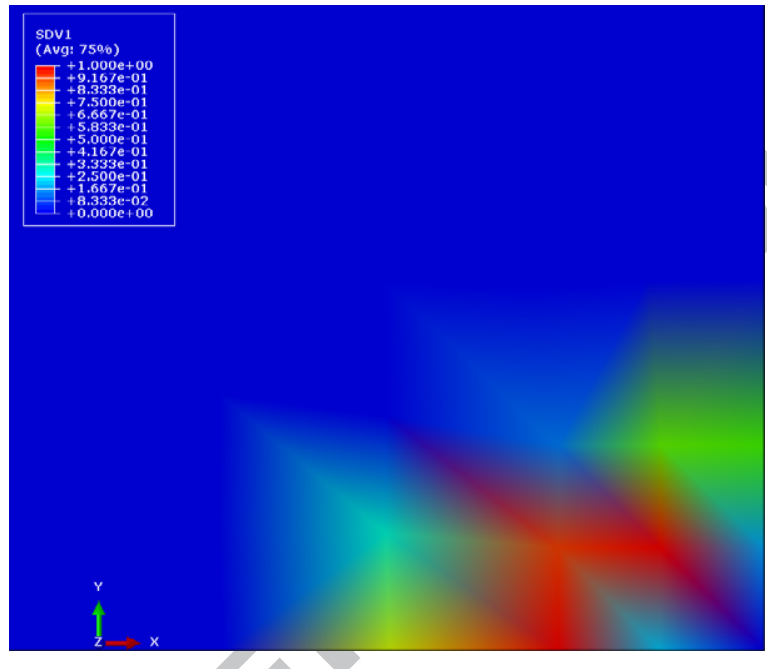

Layer -2

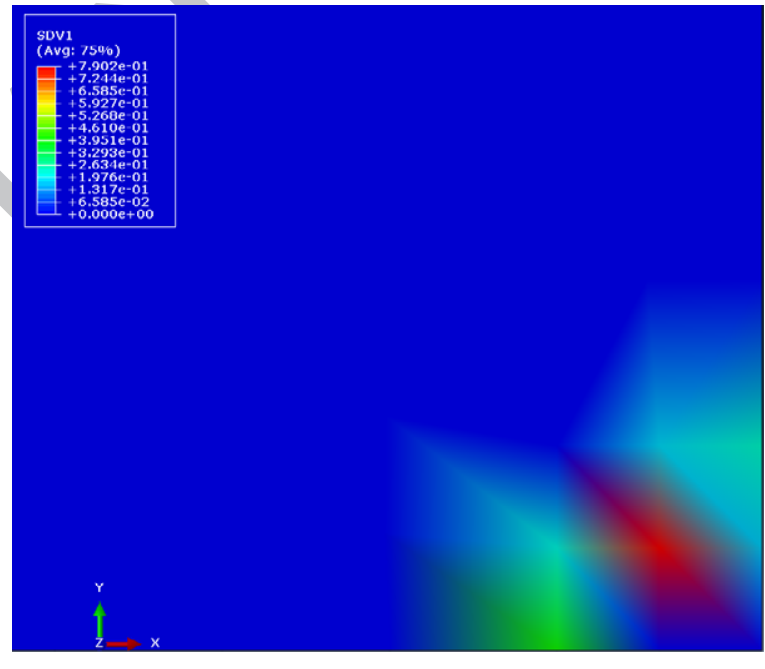

Layer-3

Figure 15: Decomposed area for the top 3 layers. 